\title{
Adult Female BALB/c Mice Heart and Aorta Tissue Under the Influence of Aqueous Extract of Physalis alkekengi
}

\author{
Mahyar Mokhatab ${ }^{1}$, Parvin Torabzadeh ${ }^{1,{ }^{*}}$ and Mona Farhadi ${ }^{2}$ \\ ${ }^{1}$ Department of Cellular-Development Biology, Karaj Branch, Islamic Azad University, Karaj, Iran \\ ${ }^{2}$ Department of Microbiology, Karaj Branch, Islamic Azad University, Karaj, Iran \\ "Corresponding author: Department of Cellular-Development Biology, Karaj Branch, Islamic Azad University, Karaj, Iran. Email: torabzadeh@kiau.ac.ir
}

Received 2021 December 19; Revised 2022 January 19; Accepted 2022 January 20.

\begin{abstract}
Background: Physalis alkekengi (PA) is used as a topical medicine in the treatment of tumors. The diuretic, laxative, and antiinflammatory properties of PA have been studied. Due to the widespread usage of PA, investigation on the plausible side effects is of great concern.

Objectives: This study was done to assess the effects of aqueous extract of PA on the heart and aortic tissue of adult BALB/c mice. Methods: Fifty BALB/c mice aged 10-12 weeks, weighing $25 \pm 2 \mathrm{~g}$, were divided into five groups of control, sham, and three experimental groups (receiving PA aqueous extract at 7, 15, and $19 \mathrm{~g} / \mathrm{Kg}$ ) for four weeks. Lactate dehydrogenase (LDH) and creatine phosphokinase (CPK) enzymes were measured. Moreover, histological processing and macroscopic investigation were performed.

Results: Our data showed that different doses of PA aqueous extract caused a significant increase in aortic diameter compared to the control and sham groups (P-value $\leq 0.05$ ). The macroscopic heart investigation revealed that the experimental groups had more apparent blood vessels than the control group. In microscopic examinations, an increase was observed in the interstitial spaces and unrecognizable stepped lines. The experimental groups demonstrated a significant decrease in the levels of LDH and CPK compared to the control and sham groups (P-value $\leq 0.5$ ). Therefore, PA aqueous extract has adverse impacts on the heart, aorta, and cardiac enzymes, which were more significant at high doses.

Conclusions: Our finding showed that PA has destructive impacts on the heart tissue and PA use needs more investigation and attention.
\end{abstract}

Keywords: Physalis alkekengi, Heart, Aorta, Creatine Phosphokinase, Lactate Dehydrogenase

\section{Background}

In some countries, medicinal plants are used to control and repel insects and eliminate parasites that cause long-lasting, damaging diseases on humans and animals $(1,2)$. Based on the World Health Organization (WHO) statistics, approximately $80 \%$ of people worldwide tend to apply herbal medicine to solve health problems (3). However, they may also have devastating side effects $(4,5)$.

Bladder cherry, Physalis alkekengi (PA), belongs to the Solanaceae family with various therapeutic properties. Anti-viral, anti-inflammatory, analgesic, and anti-bacterial properties of PA have been investigated. The anti-fever properties have also been reported (6). Phytochemical studies have demonstrated that PA contains alkaloids, polyphenol compounds (like ascorbic acid), flavonoids, and vitamin $C$, which its therapeutic impacts may be due to the presence of these compounds (7).

In Taiwan, PA is used as a topical medicine in the treatment of tumors. Their diuretic, laxative, and antiinflammatory properties have also been studied by the Middle East and Indian researchers $(8,9)$. Their analgesic properties are used for rheumatism, sore throat, and gastrointestinal pain (5).

In India, its leaves are used to treat viral hepatitis and gonorrhea, while its fruits are used to treat urinary system diseases and gout (10). In Guatemala, this plant is used to treat gonorrhea and sleep problems (4). Anti-tumor properties of PA, which act through the inhibition of topoisomerase II enzyme, were reported by Chen in 1992 (9). Moreover, a recent investigation indicated that PA could prevent the growth of human non-small-cell lung cancer cells by arresting the cells at the G2/M phase of the cell cycle (11). The effect of aqueous extract of PA fruit on the estrous cycle, reproduction, and creatine kinase enzyme (Ck-BB isozyme) in mouse uterus was investigated (12). These researchers concluded that this enzyme causes $100 \%$ distrusts and reduces the number of babies. In 2004, this group reported 
that an aqueous extract of PA reduced the activity of uterine glucose-6-phosphate dehydrogenase (G6PD) (estrogeninduced proteins) by $25 \%$ (13). Shekar-Foroosh et al. assessed the effects of PA extract on thyroid hormone and indicated that its injection at high doses increased TSH levels in mice serum (14).

\section{Objectives}

According to the extensive usage of PA extract in traditional medicine, determining possible side effects is of great importance. In reviewing the studies conducted on the effects and uses of the PA plant, it was observed that no study had been conducted to evaluate the effect of aqueous extract of this plant on heart and aorta tissues. In this study, the effects of aqueous extract of these plants on the heart and aorta tissues and changes in cardiac enzymes of mice were investigated in BALB/C mice.

\section{Methods}

\subsection{Preparation of Physalis alkekengi aqueous extract}

Fruit of the PA was collected, dried, and prepared for injection. Then, $30 \mathrm{~g}$ of the dried fruit's powder was prepared by the electric mill to which $200 \mathrm{~mL}$ of distilled water was added. The resulting suspension was slowly boiled for an hour and filtered with an ordinary paper filter. It was filtered again using Whatman paper filter No. 4 (SigmaAldrich, USA) and condensed at temperatures up to $60^{\circ} \mathrm{C}$ so that the final volume reached $20 \mathrm{~mL}$ containing $1.5 \mathrm{~g} / \mathrm{mL}$ of powdered extract.

\subsection{Animals and Experimental Design}

In this study, 50 female BALB/c mice, 10 - 12 weeks old, were purchased from the Animal Center of Pasteur Institute (Tehran, Iran). They were divided into five experimental groups as follows ( $\mathrm{n}=10$ each): control, sham, and three experimental groups and maintained under similar conditions with a 12-hour dark/light cycle and free access to standard rodent chow and water. Animal care and processing were performed in conformity with the guidelines of animal experiments by the Ethics Committee of Islamic Azad University (Code of Ethics: IR.IAU.K.REC.1396,75). Animals were kept under Guide for the Care and Use of Laboratory Animals (8th edition, National Research Council).

The experimental groups received three doses of aqueous extract, including $7 \mathrm{~g} / \mathrm{kg}, 15 \mathrm{~g} / \mathrm{kg}$, and $19 \mathrm{~g} / \mathrm{kg}$ by an intraperitoneal (IP) injection for four weeks. The sham group was injected with distilled water, and the control group received no injection. Also, $48 \mathrm{~h}$ after the last injection, mice were euthanized by carbon dioxide $\left(\mathrm{CO}_{2}\right)$ narcosis, and serum and heart samples were collected for further investigation.

\subsection{Investigating Serum Levels of $L D H$ and $C P K$}

Blood samples were taken to measure lactate dehydrogenase (LDH) and creatine phosphokinase (CPK). Next, blood samples were allowed to clot, and serum was separated using centrifugation at $4000 \mathrm{rpm}$ for 5 minutes at $4^{\circ} \mathrm{C}$. Then, the Hughes method and creatine kinase myocardial band (CPK-MB) test were used to measure LDH and CPK.

\subsection{Aorta Measurement and Histopathological Assessment}

After removing the hearts and aortas from the dead mice, the aorta diameter for all groups was measured accurately using a caliper. The heart tissues were immediately sectioned. Next, the excised hearts from experimental groups were fixed in 10\% paraformaldehyde and embedded in paraffin. Sections were stained with hematoxylineosin (H\&E) staining to investigate the alternate heart histological features.

\subsection{Statistical Analysis}

The obtained data were analyzed using SPSS software by one-way analysis of variance (ANOVA) and Tukey's and Duncan's tests. The data are presented as the mean \pm standard deviation (S.D), and a P-value $\leq 0.05$ indicated a statistically significant difference.

\section{Results}

\subsection{Serological Investigation}

Injection of PA aqueous extract at different doses of 7, 15 , and $19 \mathrm{~g} / \mathrm{Kg}$ caused a significant decrease in the LDH enzyme in the experimental groups compared to the control and sham (P-value < 0.001) groups. Also, injection of PA aqueous extract at a dose of $19 \mathrm{~g} / \mathrm{Kg}$ significantly reduced LDH enzyme compared to the experimental group receiving $7 \mathrm{~g} / \mathrm{Kg}$ of PA aqueous extract $(\mathrm{P}$-value $<0.01$ ) (Figure $1 \mathrm{~A}$ ).

On the other hand, injection of PA aqueous extract at different doses of 7, 15, and $19 \mathrm{~g} / \mathrm{Kg}$ caused a significant reduction in CPK enzyme compared to the control and sham groups (P-value < 0.0001). However, no significant difference was observed between the experimental groups (Figure $1 \mathrm{~B})$. 
A

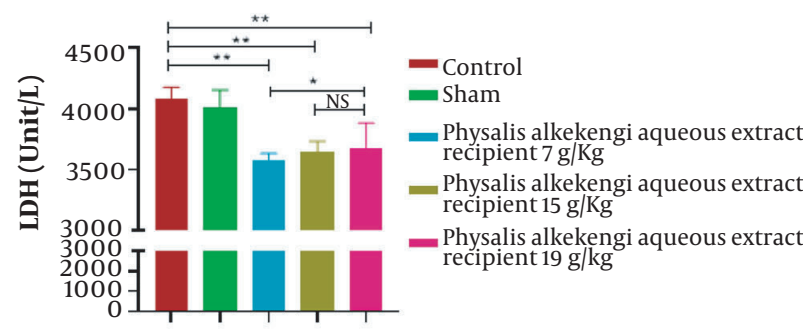

\section{B}

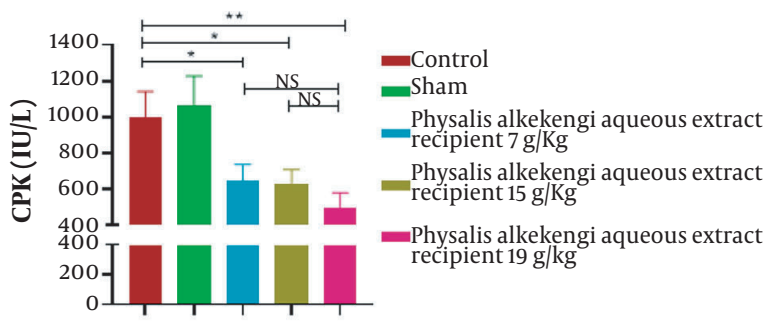

Figure 1. Serological investigation of different experimental groups. (A) Lactate dehydrogenase (LDH) measurement. (B) Creatine phosphokinase (CPK) measurement. The data are represented as the mean values \pm S.D $\left(n=10\right.$ in each group). Statistical data analysis was performed with the One-way ANOVA. NS; not significant; ${ }^{*} \mathrm{P}<0.05$ and ${ }^{* *} \mathrm{P}$ $<0.001$.

\subsection{Macroscopic Investigations of Heart Tissues}

Regarding heart tissues, it was observed that the tissues of the experimental groups, demonstrated swollen blood vessels and more significant congested aorta compared to the control and sham groups. This observation was more evident in groups exposed to higher doses of PA aqueous extract (Figure 2A). Additionally, there was a significant increase in the aortic diameter of the experimental groups receiving $15 \mathrm{~g} / \mathrm{Kg}$ and $19 \mathrm{~g} / \mathrm{Kg}$ doses of the PA aqueous extract compared to the control group (P-value $<$ $0.01)$.

\subsection{Histopathological Investigation by HEE Staining}

A microscopic view of cardiac tissue sections is shown in Figure 2B. In all experimental groups, blood vessels were smaller, and the chance of the presence of eukaryotic nuclei was lower than the control and sham groups. This decrease appeared to be more visible with the increase of dose. Moreover, the increase in interstitial spaces was illustrated in all experimental groups compared to the control and sham groups, with being more significant by increasing the PA dose. Stepped lines in the experimental groups were indistinguishable, indicating increased myocyte injury and inflammation.

\section{Discussion}

Human use of medicinal plants against diseases, repel insects, and parasites that harm humans have a long history. Nowadays, more than $80 \%$ of people apply herbs for their therapeutic approaches. In addition, many chemical drugs are modeled on herbal substances (15). The use of medicinal plants should be very prudent because many of them have not been assessed for purity and potency and may contain some substances that result in adverse side effects (16).
PA is a herbaceous plant with the potential of treating urinary tract diseases, gout, and rheumatism due to its anti-inflammatory, anti-bacterial, analgesic, laxative, diuretic, and antimitotic properties. Recent investigations have demonstrated that PA positively impacts some cancers, thyroid hormones, liver enzymes, and sexual and reproductive hormones (17-20).

In this study, the effects of PA aqueous extract were investigated on the heart tissue and aorta of adult female BALB/C mice at three different doses of 7,15, and $19 \mathrm{~g} / \mathrm{Kg}$.

Investigation of aortic diameter revealed that PA aqueous extract caused a significant increase in aortic diameter compared to the control group. It was also observed that the experimental groups, compared to the control group, had more swollen and apparent blood vessels and more congested and enlarged aorta. In the microscopic examination, increased interstitial spaces reduced blood vessels and eukaryotic nuclei, and unrecognizable stepped lines were indicated compared to the control group. Similarly, another investigation by Perk et al. revealed that treatment of Wistar rats with lyophilized fruit juice of Physalis peruviana $\mathrm{L}$ (PPL) resulted in cardiac toxicity by increasing the cardiac troponin and serum potassium levels in male Wistar rats but had no significant impacts on female Wistar rats (21).

On the other hand, our research showed that PA aqueous extract caused changes in LDH and CPK as cardiac enzymes; thus, it can be concluded that this extract caused damage to the heart. Tissue damage to the heart and aorta indicates that LDH and CPK enzymes are first increased and caused degradation in the tissue; then, considering two days of rest after the final injections, the levels of these enzymes fell below normal. This negative impact was more remarkable at high doses. Vesal et al. assessed the antagonistic estradiol effect of aqueous extract of PA fruit on the brain and showed that the aqueous extract might inhibit the release of gonadotrophin hormones of the hypothala- 
A
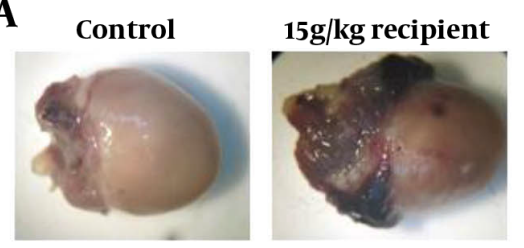

$19 g / \mathrm{kg}$ recipient

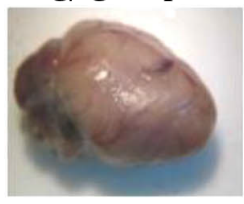

C

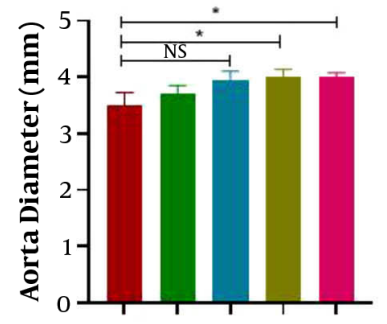

B
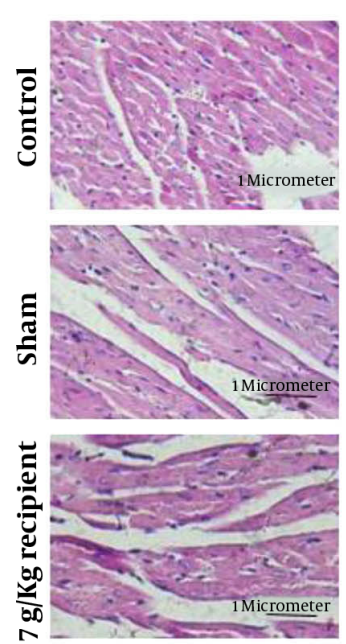
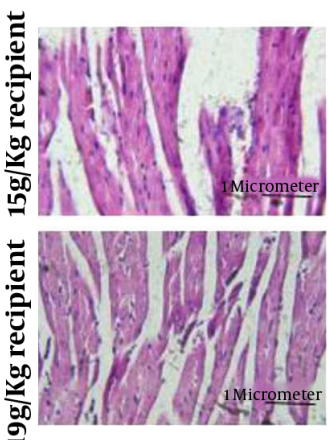

Figure 2. H\&E sections, heart tissues, and aortal diameter of the experimental groups. (A) The macroscopic evaluation of heart tissues. (B) H\&E staining with 400x magnification (C) Aortal diameter measurement. The data are represented as the mean values \pm S.D ( $n=10$ in each group). Statistical data analysis was performed with the One-way ANOVA. NS; not significant, and ${ }^{*} \mathrm{P}<0.05$

mus and release of luteinizing hormone of the hypothalamus (13). According to another investigation by Vessal et al. on the effect of aqueous extract of PA fruit on the estrous cycle, reproduction, and creatine kinase (Ck-BB isozyme) in rat's uterus caused $100 \%$ production of diestrus, reduction of the number of babies, and plasma progesterone. Also, the activity of creatine kinase $1 \mathrm{BB}$ in the uterus was inhibited time-dependently (12).

Additionally, Montaseri et al. assessed the effect of alcoholic extract of PA on female rats and showed that this extract has a negative effect on fertility and ovulation in female rats (22). Javdan et al. showed that using an aqueous extract of PA can negatively impact the growth of embryos and differentiation of some cells (23). The results of our research indicated that due to the reduction in cardiac enzymes and blood vessel swelling after the injection of PA aqueous extract, it is possible that this extract can harm embryonic enzymes and the differentiation of cells. Moreover, an investigation by Shekar-Foroosh et al. to evaluate the effect of PA aqueous extract on the thyroid hormone suggested that its injection at high doses causes an increase in thyroid-stimulating hormone (TSH) serum levels (14).

Although PA aqueous extract has anti-bacterial, antiparasitic, anti-fungal, and anti-cancer properties, its administration in female BALB/c mice showed adverse effects on the heart and aorta with a significant reduction in LDH and CPK enzymes.

\subsection{Conclusions}

Although the PA has been used as a beneficial herbal medicine in Iran and other countries, it should be considered that its use may have adverse impacts. In this study, we demonstrated that the aqueous extract of this plant could have a detrimental effect on the heart, aorta, and cardiac enzymes. To be more precise, further investigations on molecular mechanisms are suggested.

\section{Footnotes}

Authors' Contribution: Mahyar Mokhatab was responsible for concept/design, in vivo experiments, data collection, statistics, drafting of the article, approval of the article. Mona Farhadi performed data collection and drafting of the article. Parvin Torabzadeh was responsible for concept/design, and had full access to all the data and took responsibility for the integrity of the data and the accuracy of the data analysis.

Conflict of Interests: The authors declared no competing interests.

Ethical Approval: IR.IAU.K.REC.1396,75.

Funding/Support: Not applicable.

\section{References}

1. Roy A, Jauhari N, Bharadvaja N. Medicinal Plants as a Potential Source of Chemopreventive Agents. Anticancer Plants: Natural Products and Biotechnological Implements. Springer; 2018. p. 109-39. doi: 10.1007/978-981-10-8064-7_6. 
2. Faisal R, Shinwari L, Aziz I, Khalil AT. Therapeutic and Adverse Effects of Commonly Used Medicinal Plants: Standardization and Quality Assurance: Adverse Effects of Commonly used Herbs. Proc Pak Acad Sci: B. 2019;56(3):1-9.

3. Shirwaikar A, Verma R, Lobo R, Shirwaikar A. Phytotherapy-Safety aspects. Nat Prod Radiance. 2009;8(1):55-63.

4. Mello ACD, Afiatpour P. Presence of acethylcholine in the fruit of Physalis angulata (Solanaceae). Ciênc Cult (Säo Paulo). 1985:799-805.

5. Rahimi Shokooh A, Naghdi Badi H, Abdossi V, Mehrafarin A. Overview on the Agronomic, Phytochemical and Therapeutic traits of Bladder Cherry (Physalis alkekengi L.). J Med Plant. 2020;4(72):1-13. doi: 10.29252/jmp.4.72.S12.1.

6. Hong JM, Kwon OK, Shin IS, Song HH, Shin NR, Jeon CM, et al. Antiinflammatory activities of Physalis alkekengi var. franchetii extract through the inhibition of MMP-9 and AP-1 activation. Immunobiology. 2015;220(1):1-9. doi: 10.1016/j.imbio.2014.10.004. [PubMed: 25454812].

7. Ramadan MF. Bioactive phytochemicals, nutritional value, and functional properties of cape gooseberry (Physalis peruviana): An overview. Food Res Int. 2011;44(7):1830-6. doi: 10.1016/j.foodres.2010.12.042.

8. Khan MA, Khan H, Khan S, Mahmood T, Khan PM, Jabar A. Antiinflammatory, analgesic and antipyretic activities of Physalis minima Linn. J Enzyme Inhib Med Chem. 2009;24(3):632-7. doi: 10.1080/14756360802321120. [PubMed: 18825533].

9. Chen CF, Chiang H, Jaw SM, Kan WS. Antitumor agent, physalin F from Physalis angulata L. Anticancer Res. 1992;12(3):837-43.

10. Lim TK. Physalis angulata. Edible Medicinal And Non-Medicinal Plants. Springer; 2013. p. 283-99. doi:10.1007/978-94-007-5628-1_34.

11. Cao C, Zhu L, Chen Y, Wang CH, ShenTu JZ, Zheng YL. Physalin B induces G2/M cell cycle arrest and apoptosis in A549 human non-small-cell lung cancer cells by altering mitochondrial function. Anticancer Drugs. 2019;30(2):128-37. doi: 10.1097/CAD.0000000000000701. [PubMed: 30335624].

12. Vessal M, Mehrani HA, Hossein Omrani G. Effects of an aqueous extract of Physalis alkekengi fruit on estrus cycle, reproduction and uterine creatine kinase BB-isozyme in rats. J Ethnopharmacol. 1991;34(1):69-78. doi: 10.1016/0378-8741(91)90190-o.

13. Vesal M, Fathi N, Khoushdel Z. Effect of aqueous extract of Physalis alkekengi fruits on the activity of ovarian 3beta-and 20alphahydroxysteroid dehydrogenases in late pregnancy in rat. Iran J Med Sci. 2004;29(4):175-79.

14. Shekar-Foroosh S, Changizi-Ashtiyani S, Akbarpour B, Attari M,Zarei A, Ramazani M. The effect of alcoholic extract of physalis alkekengi on serum concentration of thyroid hormones in rats. Zahedan J Res Med Sci. 2012;14(5).

15. Alkhamaiseh SI, Aljofan M. Prevalence of use and reported side effects of herbal medicine among adults in Saudi Arabia. Complement Ther Med. 2020;48:102255. doi: 10.1016/j.ctim.2019.102255. [PubMed: 31987234].

16. Mosihuzzaman M. Herbal Medicine in Healthcare-An Overview. Nat Prod Commun. 2012;7(6). doi:10.1177/1934578x1200700628.

17. Gharib Naseri MK, Mohammadian M, Gharib Naseri Pharm Z. Antispasmodic effect of Physalis alkekengi fruit extract on rat uterus. Int J Reprod Biomed. 2008;6(5):193-0.

18. Namjoyan F, Jahangiri A, Azemi ME, Arkian E, Mousavi H. Inhibitory Effects of Physalis alkekengi L., Alcea rosea L., Bunium persicum B. Fedtsch. and Marrubium vulgare L. on Mushroom Tyrosinase. Jundishapur J Nat Pharm Prod. 2015;10(1). e23356. doi: 10.17795/jjnpp23356. [PubMed: 25866725]. [PubMed Central: PMC4386320].

19. Bahmani M, Rafieian-Kopaei M, Naghdi N, Nejad ASM, Afsordeh O. Physalis alkekengi: a review of its therapeutic effects. J Chem Pharm Sci. 2016;9(3):1472-85. doi: 10.29252/jmp.4.72.S12.1.

20. Bastos GN, Silveira AJ, Salgado CG, Picanco-Diniz DL, do Nascimento JL. Physalis angulata extract exerts anti-inflammatory effects in rats by inhibiting different pathways. J Ethnopharmacol. 2008;118(2):24651. doi: 10.1016/j.jep.2008.04.005. [PubMed: 18513903].

21. Perk BO, Ilgin S, Atli O, Duymus HG, Sirmagul B. Acute and Subchronic Toxic Effects of the Fruits of Physalis peruviana L. Evid Based Complement Alternat Med. 2013;2013:707285. doi: 10.1155/2013/707285. [PubMed: 24369482]. [PubMed Central: PMC3863561].

22. Montaseri A, Pourheydar M, Khazaei M, Ghorbani R. Anti-fertility effects of Physalis alkekengi alcoholic extract in female rat. Int J Reprod Biomed. 2007;5(1):13-16.

23. Nasimi M, Heydari Nasrabadi M, Shiravi A. [Effects of (Physalis Alkekengi) Fruit's Alcoholic Extract on Development of Placentas in Pregnant Wistar Rats]. J Anim Biol. 2009;1(2):51-60. Persian. 